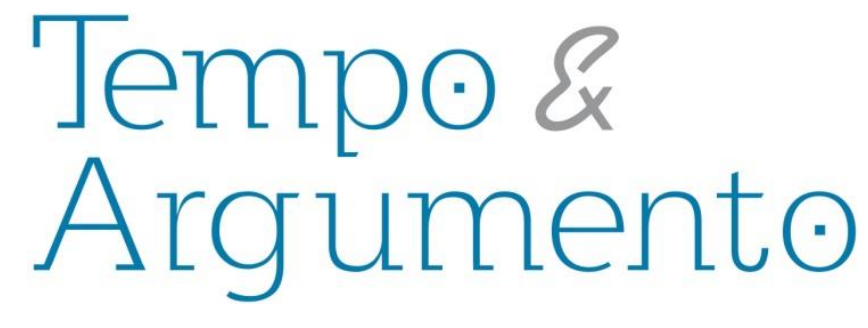

\title{
Por uma concepção mais ampla de Estado
}

\section{Resenha da obra:}

BOURDIEU, Pierre. Sobre o estado: cursos no Collège de France (1989-1992). Tradução Rosa Freire d'Aguiar. São Paulo: Companhia das Letras, 2014, 573 p.

Autor:

José Carlos da Silva Cardozo

Doutor em História Latino-Americana pela UNISINOS.

Bolsista Capes/MEC e Editor da Revista Brasileira de História \& Ciências Sociais.

Brasil

jcs.cardozo@gmail.com

\section{Para citar esta resenha:}

CARDOZO, José Carlos da Silva. Por uma concepção mais ampla de Estado. Revista Tempo e Argumento, Florianópolis, v. 7, n.15, p. 249 - 255, maio/ago. 2015.

DOI: $10.5965 / 2175180307152015249$

http://dx.doi.org/10.5965/2175180307152015249 
Mais presente do que nunca, a leitura da obra de Pierre Bourdieu (1930-2002) se torna cada vez mais relevante, principalmente nos dias de hoje quando os Estados europeus aceitam a submissão do campo político pelo econômico. No final da década de 90 do século passado, não foi diferente na França que presenciou, por vários dias, a greve de trabalhadores ligados aos setores público e privado (juntos com os estudantes) que fizeram frente à reforma nas aposentadorias defendidas pelo primeiro ministro à época.

Bourdieu é autor de uma vasta obra' na área de ciências humanas, com destaque para as ligadas à Sociologia; atualmente é o segundo intelectual francês mais citado no mundo ${ }^{2}$ e o sociólogo contemporâneo mais citado no mundo ${ }^{3}$. Mesmo sendo filho de pais camponeses, conseguiu galgar posições no campo educacional francês, se graduando em Filosofia na renomada Escola Normal Superior ${ }^{4}$, chegando a ocupar a função de professor no Collège de France - ponto máximo na carreira acadêmica - e fundando um dos periódicos de maior prestígio no campo científico Actes de la Recherche en Sciences Sociales. Seus conceitos como campo, habitus, reprodução social, capital(is) e violência simbólica são atualmente apropriados pelas várias áreas das ciências humanas.

Após dez anos de sua morte, a Editora Seuil, em parceira com a Editora Raisons d'Agir, criada pelo próprio Pierre Bourdieu, deram início à publicação dos cursos e seminários ministrados pelo sociólogo no Collège de France com o lançamento do livro que reúne as aulas do período 1989-1992, intitulado Sur l'Etat, que foi publicado recentemente no Brasil com o título de Sobre o Estado: Cursos no Collège de France (1989-1992), que congrega, nesses anos, temas ministrados sobre a questão do Estado.

\footnotetext{
${ }^{1}$ Mesmo depois de sua morte, ainda não é possível saber ao certo o número de livros e artigos que escreveu, calcula-se que, aproximadamente, 37 livros e 400 artigos.

${ }^{2}$ Informações disponíveis no Instituto de Informação Científica da Thomson Reuters, instituição que acompanha o número de citações em publicações acadêmicas. Ver: http://ip-science.thomsonreuters.com/

${ }^{3}$ Segundo informações disponíveis no Social Sciences Citation Index do Instituto de Informação Científica da Thomson Reuters. Ver: http://ip-science.thomsonreuters.com/cgi-bin/jrnlst/jloptions.cgi?PC=SS

${ }^{4} \mathrm{Na}$ época, eram o curso e a instituição de maior prestígio na área de humanidades e ciências na França, país em que o sistema de ensino superior se diferencia dos demais países pela convivência entre as universidades e as grandes escolas; estas últimas com ingresso limitado, formando a elite do mundo intelectual, político, empresarial e da administração pública. Obtiveram grau na mesma instituição os filósofos Jean Paul Sartre, Jacques Derrida, Michel Foucault e Louis Althusser; os políticos Georges Pompidou, Léon Blum e Jean Jaurés; os cientistas Louis Pasteur e Laurent Lafforgue; e os sociólogos Emile Durkheim, Raymond Aron e Pierre Bourdieu. O sistema de grandes escolas foi tema analisado por Pierre Bourdieu em La noblesse d'État: grandes écoles et esprit de corps. Paris/FR: Minuit, 1989.
} 
Aqueles que estudam seus escritos reconhecem que os mesmos possuem um alto grau de erudição e exigem, ao mesmo tempo, um elevado grau de maturidade intelectual. Talvez pela necessidade de afirmação da área de Sociologia no campo acadêmico francês, Pierre Bourdieu escreveu com alto grau de erudição, advindo do estilo retórico da Filosofia, para que sua disciplina obtivesse o reconhecimento e prestígio dentro da academia, local visto por ele como reduto, por excelência, do intelectual.

Mas o livro Sobre o Estado nos brinda com um "outro Pierre Bourdieu”, não aquele autor dos escritos, mas sim o professor que ensinou e formou gerações de investigadores por mais de 40 anos $^{5}$. Neste novo livro, podemos conferir o sociólogo pedagogo, atencioso ao seu público, explicando e reexplicando muitas vezes. Após a leitura dessas aulas, ficará complicando para seus críticos persistirem no rótulo de "pensador dogmático" dentro de um “sistema fechado de interpretação”. Pierre Bourdieu apresenta a dificuldade de comunicar suas análises a um público variado, composto tanto de sociólogos quanto por aqueles não formados em seu métier; dessa forma, esses cursos são um esforço pedagógico de explicar, não unicamente por meio de argumentos e teses, mas, sobretudo, pelas suas pesquisas e programas de pesquisas.

No livro, há várias referências à história, antropologia, literatura e direito, bem como à sociologia, na qual o autor nos conduz sobre a questão "o que é o Estado", para analisar qual o papel do Estado e do indivíduo na sociedade, permitindo ao leitor perceber a gênese do Estado e as formas de estados peculiares de cada sociedade que são analisadas para esclarecer as indagações.

Essa questão é recorrente na obra de Bourdieu, mas não chegou a compor um livro, sendo assim, a reunião dos cursos proferidos pelo autor possibilita avaliar e investigar o tema que, em última análise, é a fonte da legitimidade de todos os poderes. Para ele, o Estado é uma "ficção coletiva" que tem efeitos reais sobre os indivíduos e ao mesmo tempo se constitui como um produto e resultado de uma imbricada luta de interesses.

Em Sobre o Estado, podemos verificar a posição do autor que aos seus ouvintes tenta demonstrar a superação da oposição entre o Estado considerado opressor (teoria defendida

\footnotetext{
${ }^{5}$ Partes significativas dos sociólogos mais destacados da França se formaram com ele: Patrick Champagne, Loic Wacquant, Louis Pinto e Gisele Sapiro, entre outros.
} 
pelo marxismo) e o Estado considerado social ou do bem-estar (ideia do grupo socialdemocrata), para refletir sobre suas imbricações. Sua análise concentra-se na passagem do Estado Absolutista para o Estado Moderno, em que há a separação entre o campo político e religioso e a delimitação dos poderes, no qual está presente uma progressiva formação de campos (parlamentar, administrativo, jurídico e intelectual) nos quais há lutas internas e externas pela legitimidade e poder.

Avançando na obra, e para o melhor entendimento do leitor, dividimos a análise não por capítulo, mas sim pelos três períodos letivos universitários do Collège de France (Dezembro de 1989-Fevereiro de 1990; Janeiro-Março de 1991; Outubro-Dezembro de 1991), respeitando os programas de curso de Bourdieu.

No primeiro período, Bourdieu analisa a história social (ou como denomina "sociologia genética") das instituições do Estado, com o foco na investigação da estrutura estatal; para tanto, se vale de autores como Shmuel Noah Eisenstadt, Perry Anderson, Barrington Moore, Reinhart Bendix, Theda Skocpol e Marc Bloch para, se valendo do método comparativo, tecer apreciações sobre o estudo da gênese do Estado na Inglaterra e na França, dois casos particulares estudados dentro de um universo de casos possíveis. Ao recorrer a esses dois casos, o autor está preocupado em investigar a gêneses do "campo burocrático", assim como a forma como os diferentes recursos burocráticos são instrumentalizados e geram implicações nas lutas dento e pelo campo (com destaque para o campo político). Analisa ainda as representações do Estado e a propriedade de que o mesmo existe, sobretudo, por meio das representações; estuda a lógica da oficialização que produz um ponto de vista oficial, particular, legítimo, i.e., universal.

No segundo período, investiga o modelo de gênese do Estado derivado do acúmulo de diferentes espécies de capitais (econômico, cultural e simbólico) que permitem a emergência de um “metacapital”, possibilitando o exercício de poder sobre os outros capitais. Além do mais, o autor aponta que é no próprio Estado que se desenvolvem lutas que objetivam a obtenção do poder sobre os outros campos, principalmente naqueles em que há a regulamentação de concepções de legitimidade universais. Finaliza apontando que esse processo de concentração é um processo de universalização e monopolização, sendo a integração uma condição que evidencia uma forma de dominação efetivada na 
“monopolização do monopólio do Estado”. Para chegar a essas conclusões, Pierre Bourdieu inicia seu curso analisando três tentativas (com o mesmo se refere) de análise da gênese do Estado elaboradas por: Norbert Elias, Charles Tilly e Philip Corrigan e Derek Sayer. As duas primeiras estão ligadas à herança weberiana e à concepção economicista; já a última, ultrapassa e refina a abordagem para evidenciar o aspecto cultural no princípio do Estado moderno, a elaboração de concepções legítimas (e codificadas) que regulariam a vida social (língua nacional, tribunais etc.). Bourdieu apresenta os três "modelos parciais" para, logo em seguida, articulá-los expondo que uma das consequências do Estado é a imposição do princípio de "visão", pois o Estado é o primordial construtor de instrumentos da realidade social e de concepções universais, produtor de um "código comum", que está em relação com a sua estrutura e, consequentemente, com aqueles que o dominam.

Por fim, no último período, o autor apresenta uma tentativa de se construir um modelo de gênese do Estado; para tanto, se vale da análise, em longa duração, da construção do Estado para compreender o esforço coletivo pelo qual o Estado se faz Nação, ou seja, a construção e imposição do princípio de visão, no qual o exército e a escola possuem papel destacado, reforçando que o campo burocrático é o local e o objeto das lutas e que a Nação e o cidadão são construções ligadas ao Estado. Para alcançar tal compreensão, Pierre Bourdieu analisa o Estado dinástico e o personalismo que a casa real possui para avançar na constituição que leva a "casa do rei à razão de Estado", com o foco na ruptura das sinuosidades da apropriação pessoal de instituições estatais (e dos benefícios que delas advêm); ao final do processo é possível verificar a lógica da divisão das funções burocráticas de dominação, que possibilitam a mudança da autoridade dinástica para a autoridade burocrática por meio do corpo de agentes que se garantem e se controlam mutuamente, implicando numa divisão de trabalho de dominação que induz à formação de um campo burocrático com relativa autonomia. Essa ascensão do princípio burocrático ganha rapidez, no caso francês, com a Revolução Francesa, pela qual se unem os princípios da nova burocracia e o direito daqueles que possuem capital cultural.

A relevância do livro, como podemos acompanhar, repousa na dedicação sociológica que Bourdieu deu a todas as formas de dominação, tanto na sua gênese como em seu funcionamento, nas quais o Estado está presente. Dessa forma, o Estado não pode ser 
considerado apenas um aparelho de poder nas mãos dos dominantes e nem um espaço neutro de operacionalização dos conflitos, mas sim um “metacampo" pelo qual se constrói a representação coletiva que estrutura a vida social.

Recebido em: 16/04/2015 Aprovado em: 02/09/2015

Universidade do Estado de Santa Catarina - UDESC Programa de Pós-Graduação em História - PPGH Revista Tempo e Argumento Volume 07 - Número 15 - Ano 2015 tempoeargumento@gmail.com 